\title{
PENGEMBANGAN MODEL PEMBELAJARAN PPKn QUANTUM TEACHING BERBASIS LINGKUNGAN MELALUI COOPERATIVE LEARNING DI SMA NEGERI KOTA YOGYAKARTA
}

\author{
Oleh: \\ Nuryati* Ahmad Nasir Ari bowo* \\ Universitas Cokroaminoto Yogyakarta
}

\begin{abstract}
Abstrak
Latar belakang penelitian ini adalah banyaknya guru dalam melaksanakan pembelajaran, kurang memaksimalkan model, dan sumber belajar. Maka tujuan pendidikan tidak tercapai. Tujuan penelitian ini untuk meningkatkan pemahaman konsep dan prestasi akademik melalui pengembangan model pembelajaran PPKn quantum teaching berbasis lingkungan di SMA Negeri Yogyakarta. Jenis penelitian adalah research and development eksperimen. Subjek ujicoba adalah kelas XI sebanyak 6 kelas.

Langkah-langkah model meliputi a) pendahuluan, b) penyajian materi, c) mengajukan, membandingkan dan menjelaskan analogi, d) pengujian analogi tim, e) test individu, f) perayaan, g) penutup. Dapat diketahui bahwa, terdapat peningkatan pemahaman konsep dan prestasi akademik melalui implementasi model pembelajaran PPKn quantum teaching berbasis lingkungan melalui cooperative learning.
\end{abstract}

Keyword: PPKn Quantum Teaching, Berbasis Lingkungan, Cooperative learning, perubahan perilaku

\section{Pendahuluan}

Pembelajaran belum dikatakan berhasil apabila guru dalam proses pembelajarannya belum bisa menerapkan model pembelajaran yang memenuhi kriteria pembelajaran aktif, inovatif, kreatif, efesien, dan menyenangkan. Sudah terbukti bahwa masih banyak sekolah sampai sekarang ini, dalam proses pembelajaran guru belum mampu menerapkan model pembelajaran yang memenuhi unsur kriteria tersebut atau belum bisa mengembangkannya. Hal ini berakibat bahwa peserta didik belum mampu memahami dan mengimplemantasikan dengan baik materi yang di peroleh. Proses pembelajaran seharusnya tidak hanya dilaksanakan dikelas saja. Akan tetapi dapat dilaksanakan dilingkungan manapun dan dengan model pendekatan yang humanis. Quantum teaching berbasis Lingkungan dapat menumbuh kembangkan motif untuk belajar dengan baik dan produktif. 
Hasil wawancara peneliti dengan siswa yang mengikuti pembelajaran PPKn di beberapa SMA Negeri Yogyakarta, dapat disimpulkan bahwa masih ada guru dalam mengajar belum memanfaatkan lingkungan sebagai media atau sumber pembelajaran secara maksimal. Selain itu model pembelajaran yang sering di gunakan adalah ceramah bervariasi, sehingga masih ada siswa yang kurang aktif dalam mengikuti pembelajaran, bahkan ada yang merasa jenuh dan mengantuk, ketika mengikuti pembelajaran. Dapat diketahui bahwa tujuan pembelajaran PPKn di SMA Negeri Yogyakarta belum tercapai secara maksimal. Sehingga perlu ada pengembangan model pembelajaran. Hal tersebut bertujuan untuk memudahkan siswa dalam mencapai tujuan pembelajaran.

Berdasarkan latar belakang masalah tersebut peneliti mencoba melakukan penelitian tentang pengembangan model pembelajaran PPKn quantum teaching berbasis lingkungan melalui cooperative learning di SMA Negeri Yogyakarta. Penelitian ini bertujuan untuk: 1) mendeskripsikan model pembelajaran PPKn yang dilaksanakan oleh guru SMA Negeri Yogyakarta. 2) mendiskripsikan pengembangan model pembelajaran PPKn quantum teaching berbasis lingkungan melalui cooperative learning di SMA Negeri Yogyakarta. 3) mendiskripsikan implementasi model pembelajaran PPKn quantum teaching berbasis lingkungan melalui cooperative learning di SMA Negeri Yogyakarta. 4) menguji dan membandingkan perbedaan pemahaman konsep dapa mata pelajaran PPKn quantum teaching yang pembelajarannya berbasis lingkungan cooperative learning di SMA Negeri Yogyakarta. 5) menguji dan membandingkan prestasi akademik pada mata pelajaran PPKn quantum teaching yang pembelajarannya berbasis lingkungan PPKn melalui cooperative learning di SMA Negeri Yogyakarta.

Banyak penelitian yang berkaitan tentang model pengembangan pembelajaran, pengembangan kurikulum, dan pengembangan materi ajar. Model pengembangan tersebut sangatlah beragam. Hasil penelitian Chien dkk. (2009), dapat disimpulkan bahwa kegiatan pembelajaran dapat meningkatkan kinerja ilmiah siswa, termasuk pengetahuan dan tingkat pemahaman. Persepsi mahasiswa dari kegiatan belajar ini tampaknya positif. Studi ini mengidentifikasi dua faktor yang menonjol dalam efek positif: siswa terlibat dalam "mobileteknologi yang didukung" pengamatan selama penyelidikan ilmiah mereka; dan siswa terlibat dalam "mobile-teknologi yang didukung" manipulasi selama penyelidikan ilmiah mereka. 
Akhirnya, kesimpulan bahwa penelitian kami telah menarik bisa merupakan panduan yang berguna bagi praktisi pendidikan yang bersangkutan dengan potensi komputasi mobile di sekolah, (Journal of education, technology and society volume 12 Issue p.344-358). Selain itu hasil penelitian Hasio dkk., (2010) menunjukkan bahwa dalam pembelajaran di suatu sekolah kelompok eksperimen mengungguli kelompok kontrol pada tes pengetahuan ekologi. Selain itu, siswa dalam kelompok eksperimen merasa puas dengan sistem pembelajaran ekologi didukung oleh sistem penentuan posisi. Implikasi pedagogis dari penelitian ini adalah bahwa siswa perlu pengalaman langsung untuk memperoleh pemahaman tentang suatu topik tertentu (Journal of education, technology and society volume 13 Issue 4 p.98-111).

Hasil penelitian Sarjono dkk., (2014) tentang management development of economic learning that is based on environment with innovative approach at sma muhammadiyah Surakarta dapat di simpulkan bahwa The research results showed that: 1) Economics learning model that is based on environment with efective and adaptable through the steps, those are: a) introduction, b) the presentation of substantive material, c) proposing, comparing and explaining analogy, d) testing team, e) re exploration, and f) testing direct analogy. The model showed self-awareness, demonstrating students' cooperation/work together in teams, using an objective approach in solving problems, applying religious values and building good character. 2) Implementation of economics learning model that is based on environment with inovative learning approach at SMA Muhammadiyah Surakarta has given positive effect and contribution on increasing student'concept understanding of Economics lesson, so that, tobe efective to have been conducted by teachers. 3) there is an increasing on students' academic achievement through the implementation of economics learning model that is based on environment with inovative learning approach at SMA Muhammadiyah Surakarta than before. (asia pacific journal. Vol: 1 issue xiv, june 2014). Sarjono, dkk., (2014) melakukan penelitian tentang pengembangan pengelolaan pembelajaran ekonomi berbasis dilngkungan dengan menerapkan strategi pembelajaran inovatif di SMA Muhammadiyah Surakarta. Hasilnya dapat di ketahui bahwa dengan penerapan model pembelajaran ekonomi berbasis lingkungan melalui strategi inovatif, terdapat peningkatan pemahaman konsep dan prestasi akademik siswa.

Berbagai Hasil penelitian tersebut dapat diketahui bahwa pembelajaran dengan menggunakan berbagai media, baik teknologi maupun sumber-sumber lain, dapat meningkatkan 
pembelajaran yang lebih baik dan maksimal. Persamaan penelitian sebelumnya dengan penelitian ini antara lain sama-sama menerapkan pembelajaran dengan beberapa sumber lingkungan. selain itu pembelajaran tersebut dapat meningkatkan kemampuan peserta didik dalam memahami materi. Selanjutnya perbedaan antara penelitian ini dengan penelitian terdahulu adalah dalam hal model pembelajaran. Penelitian ini menerapkan berbagai model pembelajaran yang inovatif. Salah satunya adalah menggunakan model quantum teaching dan cooperative learning. Model pembelajaran tersebut di kembangkan untuk memudahkan siswa dalam memahami materi.

\section{Metode Penelitian}

Jenis penelitian ini adalah research and development pendekatan eksperimen. Hal tersebut didasarkan pada kenyataan bahwa metode eksperimen merupakan metode yang tepat dan akurat untuk memenuhi fungsi ilmu yaitu menjelaskan, memprediksi, dan mengontrol. Metode eksperimen mempunyai struktur yang paling ketat dan transparan.

Adapun langkah-langkah modifikasi dalam penelitian ini adalah 1) studi pendahuluan 2) pengembangan, dan 3) pengujian. Penelitian ini berlokasi di SMA Negeri Yogyakarta yaitu SMA Negeri 5 dan SMA Negeri 6. yang beralamat di Yogyakarta. Subjek dalam pengembangan ini adalah guru dan siswa. Survai awal di pilih kelas XI sebanyak 2 jam mata pelajaran dalam satu minggu. Teknik analisis data yang digunakan yaitu terkait PPKn quantum teaching berbasis lingkungan melalui cooperative learning di SMA Negeri Yogyakarta. Keabsahan data dalam penelitian ini meliputi kualitatif, eksperimen, dan uji T.

\section{Penelitian dan Pembahasan}

\section{A. Hasil Pengembangan}

Adapun hasil pengembangan pembelajaran PPKn quantum teaching berbasis lingkungan melalui cooperative learning di SMA Negeri Yogyakarta meliputi tujuh tahapan antara lain:

1. Tahap pertama, merupakan tahapan pendahuluan. Hal tersebut dimaksudkan untuk mempermudah guru dalam mengimplemtasikan model pembelajaran tersebut. 
2. Tahap kedua sebagai tahap penyajian materi, merupakan tahap pokok bagi keberhasilan siswa dalam memperoleh materi. Tahap ini merupakan tahapan untuk mengarahkan pada materi materi yang akan dibahas. Ibarat sebuah rumah, maka tahap ini bisa dijadikan pintu masuknya dalam pembelajaran. sehingga dapat dikatakan bahwa tahapan ini akan menentukan tahapan berikutnya. Apabila siswa kurang memahami pada tahapan ini maka siswa tersebut akan semakin sulit mengikuti tahapan berikutnya. pengajar haruslah berhatihati dalam menyampaikan materi pada tahapan ini. Hal tersebut dimaksudkan agar siswa dapat mengikuti tahapan ini dengan baik. Dengan pendekatan konsep Taba, pengajar diharapkan lebih mudah menyampaikan tahapan ini kepada siswa. dan juga pola pikir siswa semakin berkembang. Disamping itu, agar tingkat penguasaan materi semakin meningkat maka teknik yang digunakan adalah cooperative learning tipe STAD, karena dengan pendekatan ini siswa dituntut untuk aktif dan kreatif dalam mengikuti materi.

3. Tahap ketiga, tahapan ini terdiri dari gabungan tahap analogi langsung, mengajukan analogi, perbandingan analogi, dan penjelasan analogi. Implementasi pada tahapan ini ini diawali dengan meminta siswa mengajukan atau membuat analogi langsung atas materi yang sedang dibahas melalui berbagai informasi. tahapan ini dapat menambah dan memperkaya pengetahuan serta wawasan, karena siswa mempelajari materi dari berbagai sumber terkait Pelaksanaan demokrasi di Indonesia. Selain itu memiliki fungsi untuk memfasilitasi siswa dalam proses transmisi dan transformasi terhadap materi yang sedang dibahas. Siswa dapat memperdalam materi dengan tahapan ini, dan juga mengetahui antara teori dan realitas yang ada terkait materi.

4. Tahap keempat. Tahap pengujian analogi tim. Setelah siswa mempelajari tahapan sebelumnya. Kelompok siswa diminta untuk, mendiskusikan materi, dan merangkum hasil diskusi.

5. Tahap kelima. Tahap test individu. Siswa mengerjakan soal, terkait materi yang di pelajari.

6. Tahap keenam. Tahap perayaan. Siswa dalam tim maupun individu terbaik mendapatkan penghargaan dari guru.

7. Tahap ketujuh, merupakan tahap penutup. Pengajar dan siswa bersama-sama menyimpulkan materi yang telah dipelajari kemudian pemberian informasi oleh guru terkait tindak lanjut pertemuan berikutnya. 
Implementasi model terlebih dahulu dilakukan uji coba terbatas pada kelas XI IPA 6 SMA Negeri 5 Yogyakarta. Terdapat peningkatan pemahaman konsep dan prestasi akademik dalam uji coba terbatas ini. Namun, ada revisi dalam penerapan model. Selanjutnya uji coba lebih luas di terapkan di dua kelas yaitu kelas XI IPA 5 dan XI IPA 4 di SMA Negeri 5 Yogyakarta. Dan terakhir uji coba validitas yang di lakukan di kelas XI IPA 2, XI IPA 3, dan XI IPA 4 SMA Negeri 6 Yogyakarta. Hasil ujicoba skala terbatas, hasil ujicoba skala lebih luas, dan hasil uji validitas dapat diketahui terdapat peningkatan pemahaman konsep dan prestasi akademik. Adapun peningkatan tersebut sebagaimana di paparkan dalam tabel di bawah ini.

\begin{tabular}{|l|l|l|l|l|l|l|l|}
\hline No & Aspek & $\begin{array}{c}\text { Uji coba } \\
\text { terbatas }\end{array}$ & \multicolumn{2}{|c|}{ Uji coba lebih luas } & \multicolumn{3}{|c|}{ Uji coba validitas } \\
\hline & $\begin{array}{l}\text { XI IPA 6 } \\
26 \text { siswa } \\
\text { (SMAN 6) }\end{array}$ & $\begin{array}{l}\text { XI IPA 5 } \\
\text { 28 siswa } \\
\text { (SMAN 6) }\end{array}$ & $\begin{array}{l}\text { XI IPA 4 } \\
\text { 28 siswa } \\
\text { (SMAN 6) }\end{array}$ & $\begin{array}{l}\text { XI IPA 2 } \\
\text { 30 siswa } \\
\text { (SMAN 7) }\end{array}$ & $\begin{array}{l}\text { XI IPA 3 } \\
\text { 28 siswa } \\
\text { (SMAN 7) }\end{array}$ & $\begin{array}{l}\text { X IPA 4 siswa } \\
\text { (SMAN 7) }\end{array}$ \\
\hline 1 & $\begin{array}{l}\text { Pemahaman } \\
\text { konsep }\end{array}$ & 24 siswa & 26 siswa & 28 siswa & 29 siswa & 29 siswa & 30 siswa \\
\hline 2 & $\begin{array}{l}\text { Prestasi } \\
\text { rata-rata } \\
\text { kelas }\end{array}$ & 85 & 86 & 87 & 74 & 79 & 77 \\
\hline
\end{tabular}

Tabel 1. Hasil Pengembangan Model Pembelajaran PPKn Quantum Teaching Berbasis Lingkungan melalui Cooperative Learning Tipe STAD

Berdasarkan tabel 1 di atas dapat dikemukakan bahwa dari ujicoba terbatas sampai pada ujicoba validitas tingkat pemahaman konsep PPKn dan prestasi siswa mengalami peningkatan yang berarti. Uji coba lebih luas yang dilakukan pada kelas XI IPA 5 dan XI IPA 4 memberikan hasil yang tidak jauh berbeda, demikian juga pada uji validasi yang dilakukan pada kelas XI IPA 2, XI IPA 3 dan XI IPA 4.

\section{B. Hasil Pembahasan}

\section{Model pembelajaran PPKn yang dilaksanakan oleh Guru SMA Negeri Yogyakarta.}

Model pembelajaran yang dilaksanakan oleh guru mata pelajaran PPKn kelas XI SMA Negeri 5 dan 6 Yogyakarta, masih kurang maksimal. Hal tersebut dapat diketahui bahwa rencana pelaksanaan pembelajaran kurang lengkap selama mengajar satu semester. Guru hanya mengandalkan materi buku paket dan modul atau lembar kerja siswa. Pelaksanaan pembelajaran pun juga terkesan monoton. Sehingga hasil pembelajarannya pun belum dikatakan berhasil. 


\section{Pengembangan model pembelajaran PPKn quantum teaching berbasis lingkungan melalui cooperative learning di SMA Negeri Yogyakarta}

Pengembangan model pembelajaran PPKn Quantum teaching berbasis lingkungan pada tahapan pertama masih ada beberapa sisi kelemahannya. Hal tersebut dapat diketahui pada waktu uji coba model kelas terbatas. pengajar masih belum begitu menguasai konsep model pembelajaran PPKn quantum teaching berbasis lingkungan. Selanjutnya perlu diadakan evaluasi agar menjadi lebih baik. Selanjutnya pada tahap ujicoba lebih luas pengajar sudah dapat menerapkan model pembelajaran dengan baik. Hal tersebut dapat diketahui dari perubahan pada siswa.

\section{Implementasi model pembelajaran PPKn quantum teaching berbasis lingkungan melalui cooperative learning di SMA Negeri Yogyakarta}

Implementasi model pembelajaran PPKn Quantum teaching berbasis lingkungan terlaksana dengan baik, Meskipun perlu evaluasi. Hal tersebut dapat diketahui guru dan peneliti melakukan implementasi model 6 kelas pada jenjang yang sama. Dari hasil implementasi tersebut teryata terdapat perbedaan yang signifikan pada siswa.

\section{Pemahaman konsep dan prestasi akademik pada mata pelajaran PPKn quantum teaching berbasis lingkungan melalui cooperative learning di SMA Negeri Yogyakarta}

Pemahaman konsep PPKn dan prestasi siswa mengalami peningkatan yang berarti. Ujicoba lebih luas yang dilakukan memberikan hasil yang tidak jauh berbeda, demikian juga pada uji validasi.

\section{Perbandingan dengan Hasil Penelitian Terdahulu}

Hasil penelitian Chien dkk. (2009), Witthaus (2009), Hasio dkk., (2010) dan Sarjono dkk., (2014) terkait penelitian berbasis lingkungan sebagaimana yang dipaparkan dalam uraian sebelumnya, dapat diketahui bahwa terdapat perbedaan dan persamaan dengan penelitian ini. Adapun persamaan dalam penelitian ini antara lain adalah sama-sama penelitian yang berbasis lingkungan, mempunyai dampak yang signifikan setelah diadakan penelitian, dan penelitian terfokus dalam salah satu bidang. Selanjutnya perbedaannya adalah pada penelitian terdahulu lebih menekankan pada lingkungan e-learning, mobile teknologi, sedangkan dalam penelitian ini 
lebih menekankan pada pendekatan yaitu quantum teaching dan sumber di berbagai lingkungan yang meliputi internet, buku, masyarakat, serta berbagai media. Hasil dalam penelitian ini lebih menekankan pada model pembelajaran yang inovatif.

\section{Kesimpulan}

Model pembelajaran yang dilaksanakan oleh guru mata pelajaran PPKn kelas XI SMA Negeri 5 dan 6 Yogyakarta, masih kurang maksimal. Hal tersebut dapat diketahui bahwa rencana pelaksanaan pembelajaran kurang lengkap selama mengajar satu semester. Guru hanya mengandalkan materi buku paket dan modul atau lembar kerja siswa. Pelaksanaan pembelajarn pun juga terkesan monoton. Sehingga hasil pembelajarannya pun belum dikatakan berhasil.

Pengembangan model pembelajaran PPKn quantum teaching berbasis lingkungan pada tahapan pertama masih ada beberapa sisi kelemahannya. Hal tersebut dapat diketahui pada waktu uji coba model kelas terbatas. pengajar masih belum begitu menguasai konsep model pembelajaran PPKn quantum teaching berbasis lingkungan. Selanjutnya perlu diadakan evaluasi agar menjadi lebih baik. Selanjutnya pada tahap ujicoba lebih luas pengajar sudah dapat menerapkan model pembelajaran dengan baik. Hal tersebut dapat diketahui dari perubahan pada siswa.

Implementasi model pembelajaran PPKn quantum teaching berbasis lingkungan terlaksana dengan baik, Meskipun perlu evaluasi. Hal tersebut dapat diketahui guru dan peneliti melakukan implementasi model 6 kelas pada jenjang yang sama. Dari hasil implementasi tersebut teryata terdapat perbedaan yang signifikan pada siswa. Pemahaman konsep PPKn dan prestasi siswa mengalami peningkatan yang berarti. Ujicoba lebih luas yang dilakukan memberikan hasil yang tidak jauh berbeda, demikian juga pada uji validasi.

\section{Daftar Pustaka}

Chien Liu, Tzu dkk. 2009. The effects of mobile natural-science learning based on the 5E learning cycle: A case study. Journal Educational Technology \& Society. Taiwan: Institute of Graduate Institute of Learning \& Instruction, National Central University, Taiwan // 2Institute of Education, National Chiao Tung University, Taiwan // 3 Taipei Municipal Shi-Dong Elementary School, Taiwan // 4 Department of Nature Science, Taipei Municipal University of Education. 
Hsiao, Hsien Sheng dkk. 2010. Ocation Based Services for Outdoor Ecological Learning System: Design and Implementation. Educational Technology \& Society. Taiwan: Department of Technology Application and Human Resource Development, National Taiwan Normal University, Taipei, Taiwan 1 Department of English, National Taiwan Normal University.

Sarjono, Yety, dkk., 2014. management development of economic learning that is based on environment with innovative approach at SMA Muhammadiyah Surakarta. Asia Pacific journal of research. Volume: 1 issue xiv, june 2014. (http://apjor.com/downloads/1907201413.pdf)

Witthaus, Gabrille. (2009). The Implication of SCORM Conformance for Workplace e-learning. Electronic Journal of e-Learning Volume 7 Issue 2 2009,hal 01 (183-190). England: Journal International New Leaf Training Network Ltd. 